\title{
Analysis of Temperature Characteristics of Electro-hydraulic Servo Valve Based on AMESim
}

\author{
Zeqi Chen ${ }^{\text {a }}$, Weihui Wang ${ }^{\mathrm{b}}$ \\ Xi'an High-tech research institute, Xi'an 710000, China. \\ a735218324@qq.com, bc64776689@163.com
}

Keywords: AMESim; Electro-hydraulic servo valve; Temperature; Control characteristics.

\begin{abstract}
In order to study the influence of the change of hydraulic oil temperature on the control characteristics of the electro-hydraulic servo valve, simulation analysis was carried out based on AMESim software. According to the structural characteristics and working principle of the dual-nozzle type baffle electro-hydraulic servo valve, a graphical physical model of the servo valve is established. The control variable method was used to group and set the oil viscosity parameters at different temperatures, and the results from batch processing were compared and analyzed. It shows that under low temperature conditions, the servo valve output amplitude is greatly attenuated and the hysteresis is also large. At higher temperatures, the step response speeds up, and the overshoot increases. As the temperature increases, the servo valve width and the phase width increase to varying degrees, but at the same time, the internal leakage of the valve also increases, and the increase is significant.
\end{abstract}

\section{Introduction}

Electro-hydraulic servo valve with high control accuracy and fast response speed is a high-performance electro-hydraulic control element widely used in hydraulic servo systems [1]. At the same time, electro-hydraulic servo valve as a key component of the hydraulic servo system, its performance is also a direct impact on the quality of the entire system. One of the important indicators for evaluating the performance of an electro-hydraulic servo valve is its reliability and stability over a wide temperature range [2]. It is known that changes in temperature can change the viscosity, bulk modulus, and saturated vapor pressure of the fluid, and thus change the pressure, velocity distribution, and critical conditions of cavitation in the valve chamber, ultimately resulting in a change in the control characteristics of the servo valve. [3].

Hong Zhang [4] established a hydraulic servo loading system model and simulated the hydraulic system by setting different valve opening degrees to obtain specific data on the effect of this parameter change on the dynamic characteristics of the hydraulic system. Comparing with the experimental results, the feasibility and correctness of the AMESim modeling of electro-hydraulic servo system are verified. Kang Shi [5] simulated the servo valve pressure characteristics and the flow characteristics of the valve core when the orifice is under different degrees of obstruction from the perspective of servo valve fault diagnosis. And the influence of the stuck, leaked and static friction changes on the response of the entire system. However, articles that specifically study the effects of temperature changes on the servo valve control characteristics are rarely reported.

This article also uses AMESim software, relying on its convenient graphical modeling methods and powerful multi-disciplinary capabilities, to establish a dual-nozzle baffle electro-hydraulic servo valve simulation model. By setting different temperature parameters, the change of the control characteristics of the electro-hydraulic servo valve is analyzed.

\section{Servo Valve Structure Theory and AMESim Modeling}

\subsection{Servo Valve Structure Composition.}

The double-nozzle baffle electro-hydraulic servo valve studied in this paper is also called a force feedback two-stage electro-hydraulic servo valve. Its structure principle is shown in Figure 1. 


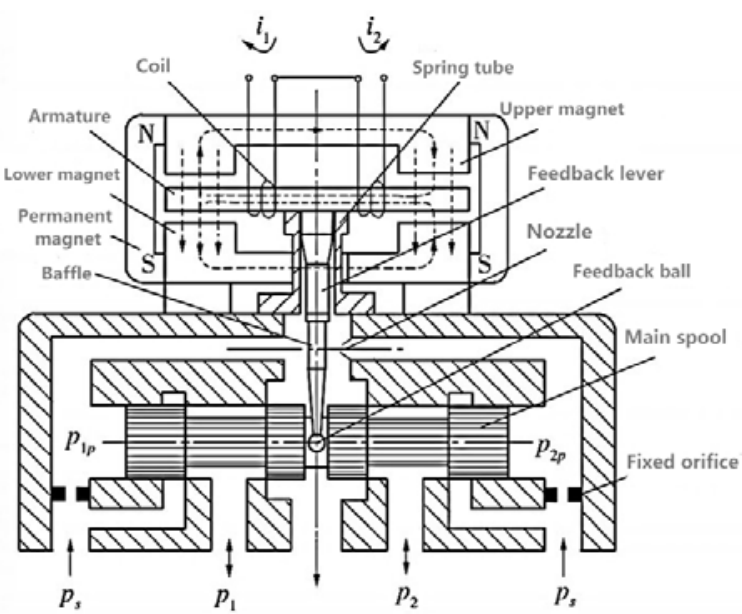

Fig 1. Double nozzle flapper types electro-hydraulic servo valve structure schematic

The servo valve is mainly composed of a permanent magnet moving iron torque motor, a pre-stage double nozzle flapper valve and a power stage four-way slide valve [6]. Among them, the pre-stage double nozzle flapper valve is controlled by a permanent magnet torque motor and is mainly used as a hydraulic pressure amplifier. The power stage spool valve controls the opening and closing of the oil circuit, direction of reversing and flow, and the displacement of the spool relates to the armature baffle through the feedback rod to form a feedback force feedback loop of the slide valve.

\subsection{Servo Valve AMESim Modeling.}

Using AMESim software for hydraulic circuit simulation, the model sketch of the servo valve should be completed first. According to the structural composition of the servo valve, it can be divided into three modules for modeling, namely torque motor, dual nozzle flapper valve, and four-way slide valve.

The first step is to model the torque motor. The torque motor is composed of a permanent magnet, armature, spring tube, control coil, and upper and lower guide magnets. According to the principle of the magnetic circuit of the torque motor, a corresponding physical model of the torque motor is built in the electromagnetic library of AMESim, as shown in Fig. 2.

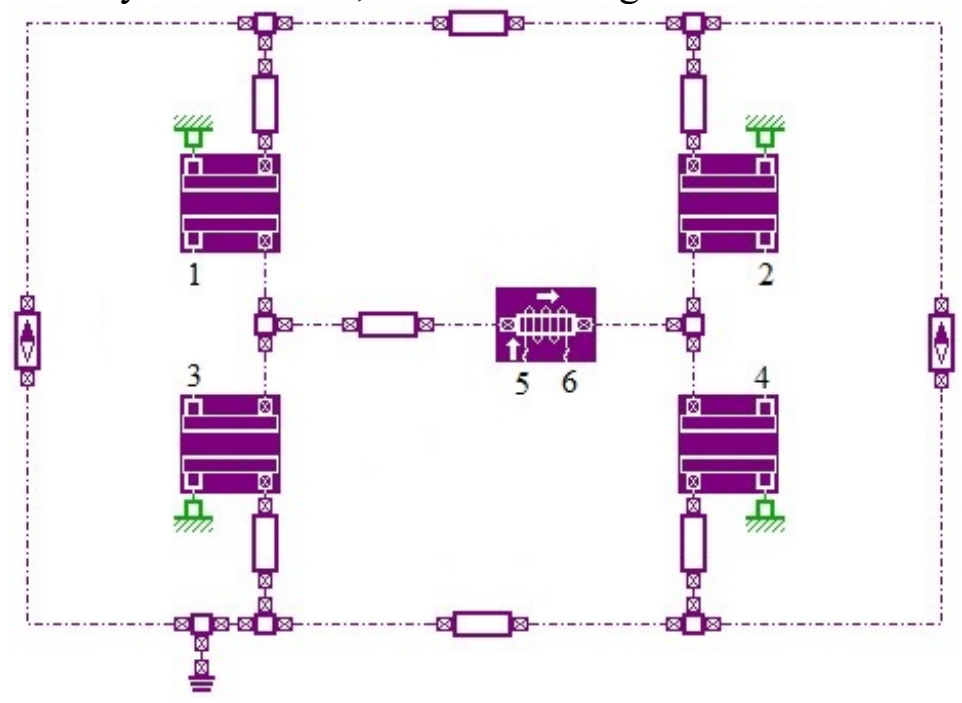

Fig 2. Torque motor model

The second step is to model the dual nozzle flapper valve. First, use the Flexure tube that comes with the Demos library to simulate spring tubes and baffles. Then, the nozzle model was established, and the spring-damping element was selected in the mechanical library to simulate the impact force of the nozzle jet on the baffle. The displacement-flow element was selected in the hydraulic library to simulate the internal leakage caused by the jet. Based on this, a fixed orifice and a return throttle orifice are added. Finally, the double nozzle flapper valve model shown in Fig. 3 is obtained. 


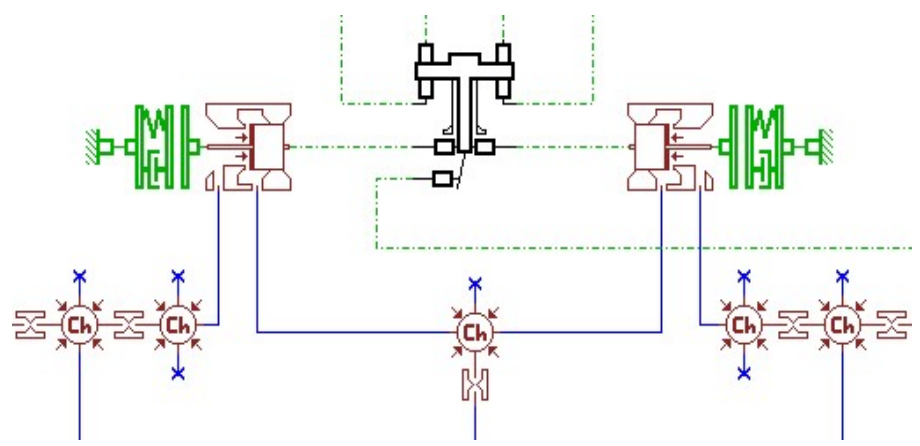

Fig 3. Double nozzle flapper valve model

The third step is to model the power stage spool valve. Since this article focuses on the temperature characteristics of the servo valve itself, many detailed factors need to be considered and refined modeling is required. Therefore, the use of hydraulic components to design the relevant parts of the library and combined hydraulic library and some components of the mechanical library to build the sliding valve model. Among them, the displacement-mass block simulates the displacement, mass, inertial force, viscous damping, and friction of the valve plug. The displacement-flow element simulates the opening of the valve opening as the spool moves. Use a volumetric module to consider the pressure pulsation factor. The constructed slide valve model is shown in Fig. 4.

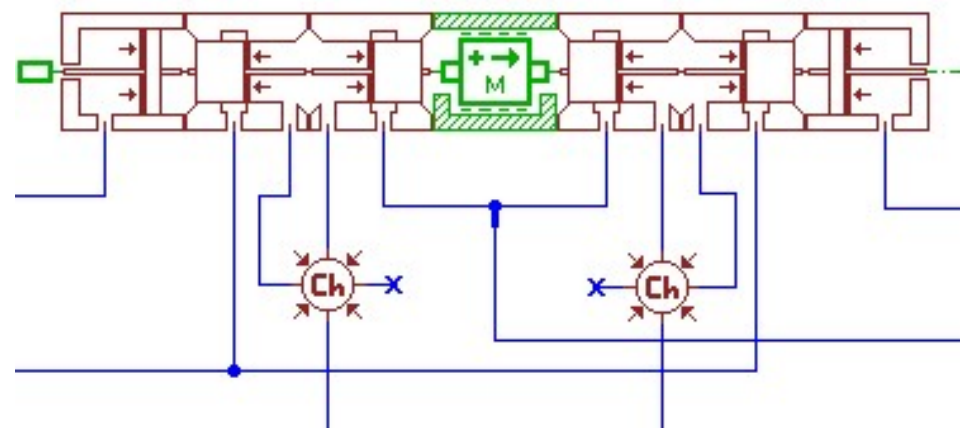

Fig 4. Power stage slide valve model

The corresponding interfaces of the above three modules are connected, and related external modules such as a signal source, an oil source, and a fuel tank are added. The AMESim simulation model of the entire servo valve is finally obtained as shown in Fig. 5.

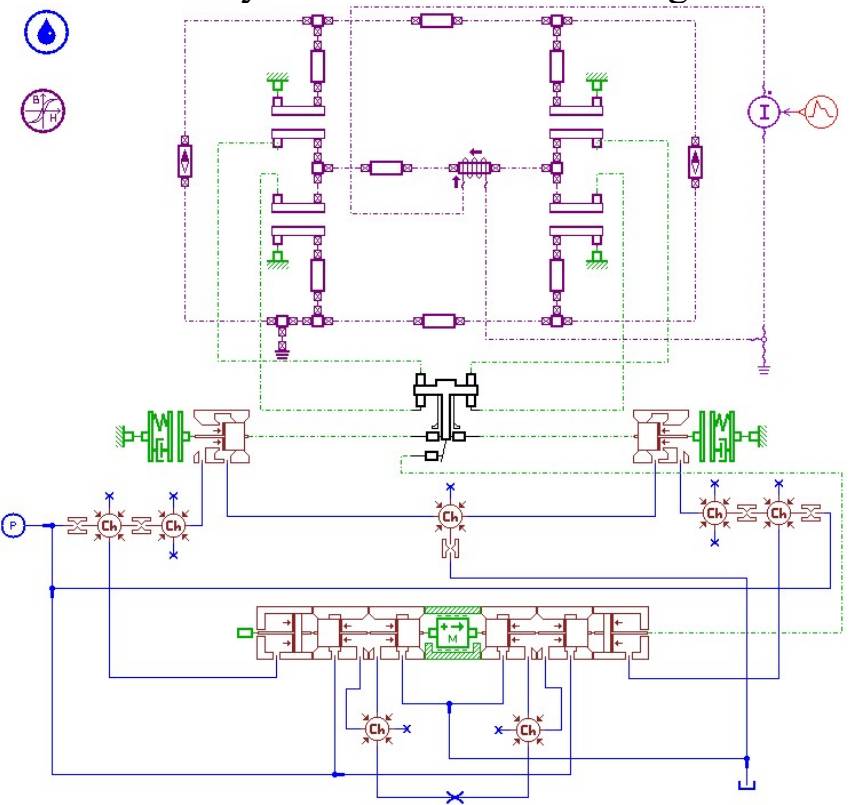

Fig 5. Servo valve overall simulation model

\subsection{Parameter Settings.}

After the sketches are set up, the components are assigned the appropriate sub-models based on structural features and simulation requirements. Here, in order to simulate the viscous friction of the 
fluid flowing in the valve, a sub-model HLO01 with frictional properties is assigned to the pipeline. Then set specific parameters for each sub-model. Table 1 shows the main technical parameters of the dual-nozzle baffle-type electro-hydraulic servo valve.

Table 1. Servo valve main technical parameters [7]

\begin{tabular}{cc}
\hline Name & Specifications and parameters \\
\hline Rated current & $10 \mathrm{~mA}$ \\
preset pressure & $21 \mathrm{Mpa}$ \\
Fixed orifice diameter & $0.35 \mathrm{~mm}$ \\
Return throttle orifice diameter & $0.8 \mathrm{~mm}$ \\
Nozzle diameter & $0.45 \mathrm{~mm}$ \\
Nozzle and baffle clearance & $0.08 \mathrm{~mm}$ \\
Slide valve diameter & $10 \mathrm{~mm}$ \\
Piston rod diameter & $5 \mathrm{~mm}$ \\
Valve core equivalent quality & $0.01 \mathrm{Kg}$ \\
Spool travel & $\pm 0.5 \mathrm{~mm}$ \\
Viscous friction coefficient & $50 \mathrm{~N} /(\mathrm{m} / \mathrm{s})$ \\
Flow Coefficient & 0.572 \\
\hline
\end{tabular}

\section{Temperature Characteristics Analysis}

Temperature can change the viscosity, bulk modulus, saturated vapor pressure, and solubility of air in hydraulic fluids. The viscosity change has the most significant influence on the flow field, and the servo valve control characteristics are closely related to the flow field distribution. Therefore, starting from the viscosity, this paper analyzes the influence of temperature on the control characteristics of the valve by changing the oil viscosity. No. 12 aviation hydraulic oil is used as the hydraulic medium for the circuit. The viscosity values at different temperatures are shown in Table 2. Also, for ease of comparison, the five sets of parameters for the two variables of temperature and kinetic viscosity are batch processed in AMESim.

Table 2. No. 12 aviation hydraulic oil viscosity parameter [8]

\begin{tabular}{cc}
\hline Temperature $\left({ }^{\circ} \mathrm{C}\right)$ & dynamic viscosity $(\mathrm{cP})$ \\
\hline-40 & 493.8 \\
-20 & 102.5 \\
0 & 40.1 \\
30 & 21.8 \\
50 & 10.2 \\
\hline
\end{tabular}

\subsection{Step Response and Ramp Response}

By parameter setting the signal source, a step signal with a size of $10 \mathrm{~mA}$ and a ramp signal varying from $-10 \mathrm{~mA}$ to $10 \mathrm{~mA}$, which starts from $0 \mathrm{~s}$, are sequentially added to the system. Set the simulation time to $2 \mathrm{~s}$, the print interval to $0.001 \mathrm{~s}$, and run the simulation to obtain the servo valve's flow step response and ramp response curve as shown in Fig. 6.

From the step-response curve, it can be seen that the servo valve response time is longer at lower temperatures, especially at $-40^{\circ} \mathrm{C}$ for $40 \mathrm{Ms}$. As the temperature of the fluid increases, the response time decreases, but after $0^{\circ} \mathrm{C}$, the response time is no longer significant. Also, as the temperature rises, the overshoot in the step response process also increases, which will lead to increased valve core vibration. In addition, at lower temperatures, there is an important drawback to the step response of the servo valve, which is a large degree of attenuation of the output flow amplitude. The reason is that at low temperatures, the viscosity of the oil is large and the viscous friction is significant, resulting in a greatly reduced flow rate of the oil in the valve. 


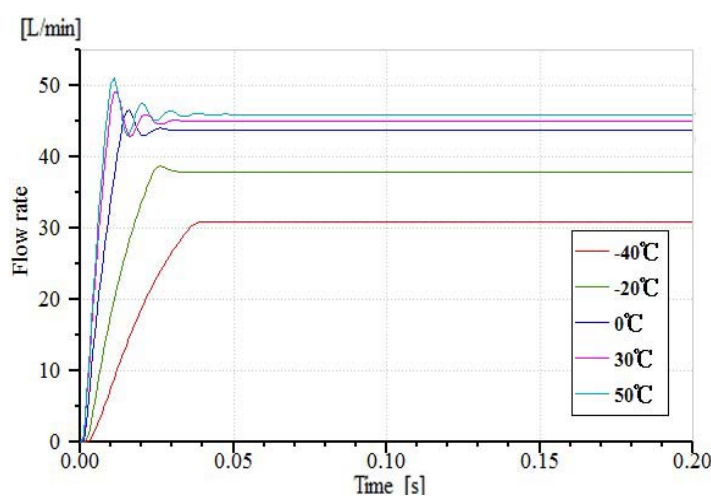

(a) Step response curve

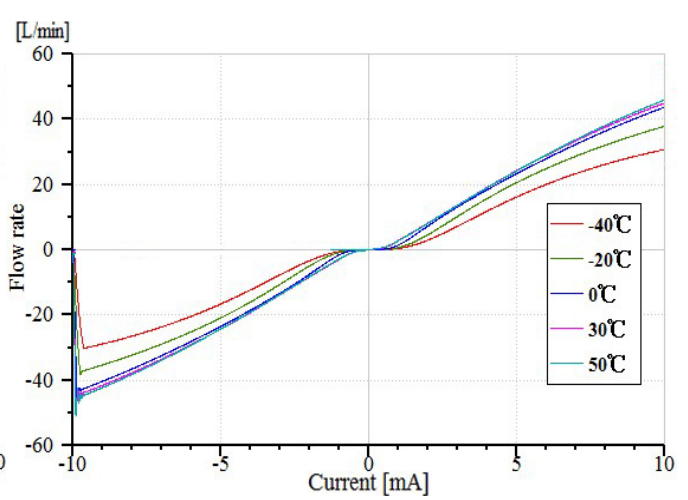

(b) Ramp response curve

Fig 6. Servo valve step response and ramp response

Observing the ramp response curve, it can be seen that for the ramp signal, the servo valve also has the above-mentioned case of large-valued attenuation at low temperatures, and the lower the temperature, the smaller the flow gain of the servo valve. In addition, when the input current is changed from $-1 \mathrm{~mA}$ to $1 \mathrm{~mA}$ near $0 \mathrm{~mA}$, the output flow rate remains unchanged at $0 \mathrm{~L} / \mathrm{min}$, and there is a dead zone because the servo valve is designed as a negative opening type when the model is built.

Based on the above ramp signal, after the input current reaches $10 \mathrm{~mA}$, it continues to change from $10 \mathrm{~mA}$ to $-10 \mathrm{~mA}$ uniformly, that is, the servo valve is loaded with a circulating current signal, and the hysteresis of the servo valve can be observed. Fig. 7 shows the hysteresis loop formed by the servo valve at different temperatures. From the figure, it can be seen that the hysteresis loop is the largest at $-40^{\circ} \mathrm{C}$, which is about $6.2 \%$. As the temperature rises, the hysteresis loop gradually decreases and is only $2.3 \%$ at $50^{\circ} \mathrm{C}$.

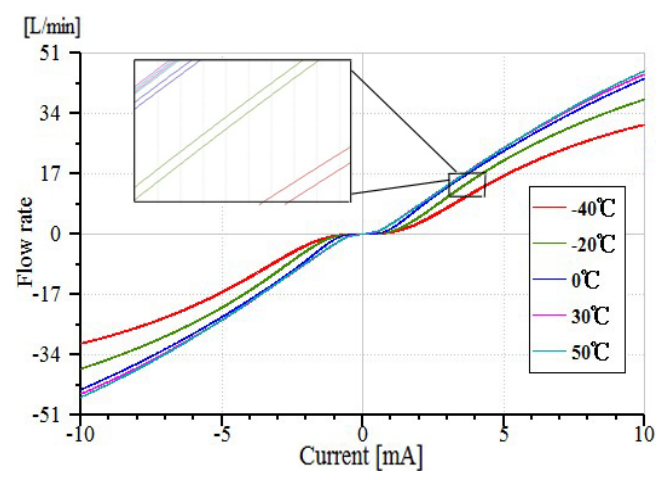

Fig 7. Hysteresis of servo valve at different temperatures

\subsection{Frequency Characteristics}

In Fig. 5, a fixed orifice is connected between the two control ports of the servo valve, and the servo valve is operated under no-load conditions. Therefore, the servo valve's no-load flow characteristic curve is also obtained in section 2.1. Next, the fixed orifice was replaced with a hydraulic cylinder with a load, and the signal source was replaced with a sinusoidal current signal with a frequency of $1 \mathrm{~Hz}$ and an amplitude of $10 \mathrm{~mA}$. The batch operation simulation was performed, and the speed response curve of the load connected to the hydraulic cylinder was shown in Fig. 8.

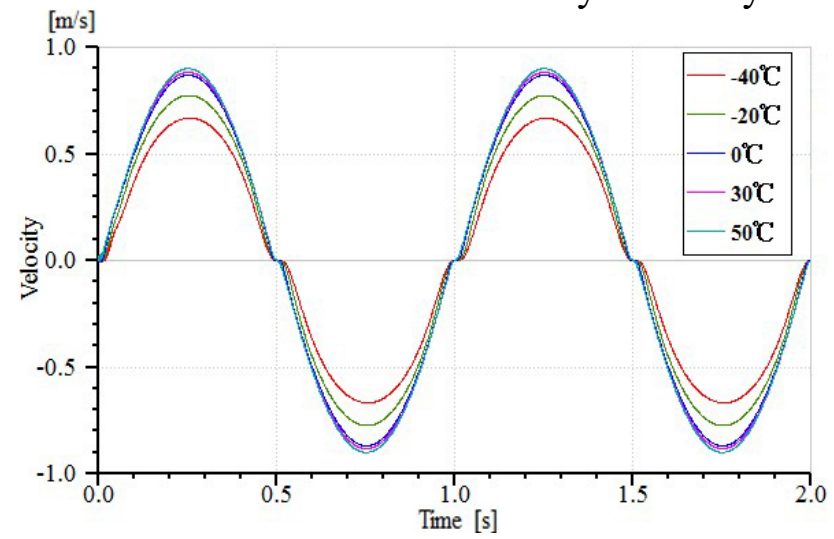

Fig 8 . The speed response of the load at different temperatures 
In order to make the input and output amplitudes the same, it is easy to draw the Bode diagram, modify the amplitude of the signal source to 0.9 , and connect the proportional part with $\mathrm{k}=1 / 90$ in series to ensure that the current amplitude input to the torque motor is unchanged at $10 \mathrm{~mA}$. In the linear analysis mode, the sinusoidal input signal is used as the control variable, and the load speed response is the observed variable. The frequency characteristic curve shown in Fig. 9 is plotted. The upper half of the figure is the amplitude-frequency characteristic curve, and the lower half is the phase-frequency characteristic curve. It can be seen that at $0^{\circ} \mathrm{C}$, the servo valve has a width of 124 to $128 \mathrm{~Hz}$ and a phase width of 78 to $83 \mathrm{~Hz}$.

In the same way, the frequency characteristic curve of the servo valve at different temperatures can be drawn in turn, and the corresponding frequency bandwidth of the servo valve can be obtained as shown in Table 3. From the data in the table, it can be known that as the temperature increases, the amplitude and frequency bandwidth of the servo valve are increased, which means that the dynamic performance of the servo valve is improved. When the temperature rises to $0^{\circ} \mathrm{C}$, the amplitude bandwidth increases slowly, and the improvement of dynamic characteristics is no longer obvious. Among them, at $-40{ }^{\circ} \mathrm{C}$, the amplitude width of the servo valve is zero, because at this temperature, the servo valve output amplitude is seriously attenuated, which is less than $70.7 \%$ of the input signal and does not meet the working requirements.
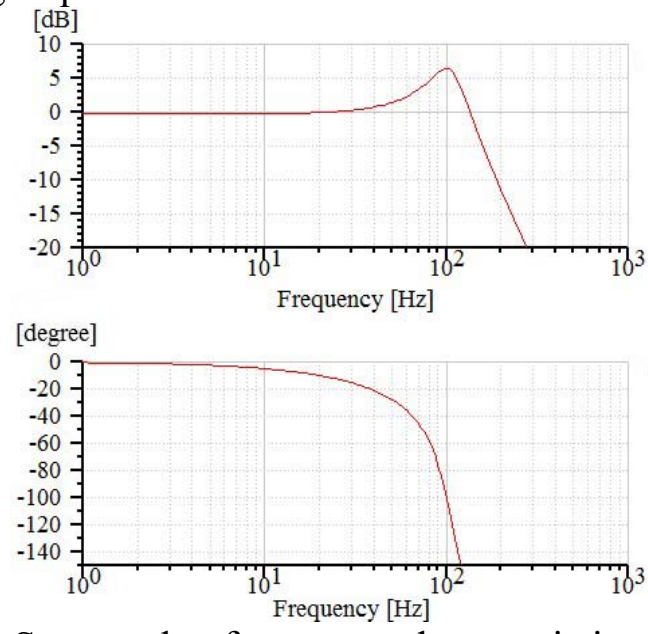

Fig 9. Servo valve frequency characteristics at $0^{\circ} \mathrm{C}$

Table 3. Servo valve bandwidth at different temperatures

\begin{tabular}{ccc}
\hline Temperature $\left({ }^{\circ} \mathrm{C}\right)$ & Amplitude bandwidth(rad/s) & Phase bandwidth(rad/s) \\
\hline-40 & 0 & $46 \sim 50$ \\
-20 & $40 \sim 45$ & $60 \sim 65$ \\
0 & $124 \sim 128$ & $78 \sim 83$ \\
30 & $130 \sim 135$ & $88 \sim 92$ \\
50 & $133 \sim 138$ & $96 \sim 100$ \\
\hline
\end{tabular}

\subsection{Internal Leakage Characteristics}

Internal leakage flow is the total flow out of the oil return port when the load flow is zero. For two-stage servo valves, the internal leakage flow includes pre-stage leakage flow and power-level leakage flow [9]. Mainly for the pre-level leakage flow analysis here. Fig 10 shows the time-varying curve of the internal leakage flow of the servo valve pre-stage under different temperature conditions under the action of a sinusoidal signal in section 3.2.

From the curve in the figure, it is easy to see that as the temperature rises, the internal leakage flow of the servo valve also increases and increases rapidly. The internal leakage flow at $50^{\circ} \mathrm{C}$ has exceeded 4 times at $-40^{\circ} \mathrm{C}$. 


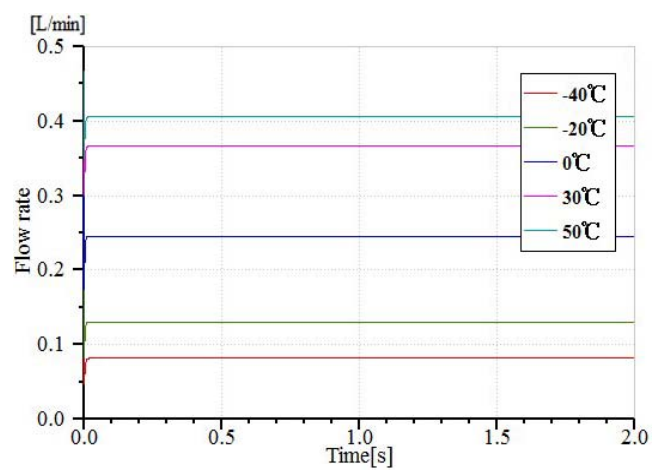

Fig 10. Internal leakage characteristics at different temperatures

\section{Summary}

As the temperature rises, the viscosity of the hydraulic oil decreases, and the step response speed of the servo valve increases, but at the same time, the overshoot amount increases, which means that the valve core vibration increases in response. When the temperature is lower, the amplitude of the output flow of the servo valve is greatly attenuated, and the hysteresis is also large. Especially when the amplitude is greatly attenuated, the servo valve control characteristics will be seriously affected. As the temperature rises, the servo-valve's amplitude width and phase-frequency width increase to different extents. When the temperature rises to $0^{\circ} \mathrm{C}$, the bandwidth increases slowly and tends to be saturated. As the temperature rises, the amount of internal leakage of the valve also increases, and the increase is significant.

In summary, the temperature change has a significant influence on the control characteristics of the servo valve. It is advisable to control the hydraulic oil temperature within the range of $0^{\circ} \mathrm{C}$ to $30^{\circ} \mathrm{C}$.

\section{References}

[1]. Slouched Wang. Jurying Duane, et al. Hydraulic components and selection [M]. Beijing: Chemical Industry Press, 2007:400-401.

[2]. Chili Ma, Feng Li, et al. Analysis of Flow Field of Nozzle Baffle Valve under Different Temperature Conditions [J]. Hydraulic and pneumatic, 2014, 9:78-81.

[3]. Quant Liang, Quoin Su, et al. Hydraulic System AMESim Computer Simulation Guide [M]. Beijing: Machinery Industry Press, 2014.

[4]. Hong Zhang, Ming Gao, et al. Influence of Servo Valve Opening Degree on Dynamic Characteristics of Electro-hydraulic Servo System [J]. Hydraulic Pneumatic and Sealing,2015,10:27-30.

[5]. Kang Shi. Fault Diagnosis of Electro-hydraulic Servo System Based on AMESim Simulation [D]. Wuhan: Wuhan University of Science and Technology, 2009.

[6]. Lipping Zhang. Hydraulic valve principle, use and maintenance [M]. Beijing: Chemical Industry Press, 2015.

[7]. Chinghai Liu. Modeling and Simulation of Two-stage Force Feedback Nozzle Baffle Servo Valve [D]. Harbin: Harbin Institute of Technology Master Thesis, 2013.

[8]. China Aviation Material Handbook Editorial Committee. China Aviation Material Handbook [M]. Beijing: China Standard Press, 1989.

[9]. Chunking Wang. Hydraulic control system [M]. Beijing: Machinery Industry Press, 2014. 